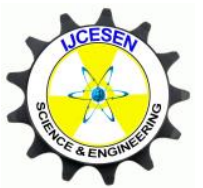

Copyright C IJCESEN
International Journal of Computational and

Experimental $\boldsymbol{S}$ cience and $\boldsymbol{E}$ ngineering

(IJCESEN)

Vol. 4-No.3 (2018) pp. 34-38

http://dergipark.gov.tr/ijcesen

Review Article

\title{
Yarns Emitting Far Infrared Rays
}

\section{İsmail YÜCE*}

Trakya University, Techinal Science Vocational School, Textile, Clothing, Shoe and Leather Department, 22030 , Edirne - Turkey

* Corresponding Author : ismailyuce@ trakya.edu.tr ORCID: 0000-0001-6657-7169

\section{$\underline{\text { Article Info: }}$}

DOI: $10.22399 /$ ijcesen.368405

Received : 18 December 2017

Accepted : 17 November 2018

\section{Keywords:}

Bioceramic

Yarn

Infrared

Healthy textiles

\begin{abstract}
:
Infrared radiation refers to electromagnetic radiation whose wavelength is longer than visible light, but shorter than terahertz and microwave radiation. Far infrared radiation (FIR) denotes radiation that is considered a kind of infrared radiation and includes wavelengths between 5.6-1000 micron. These rays are emitted by sun rays, human body, metals and some minerals. The positive effect of these rays on human health has already been mentioned and they are widely used especially in Far East countries in textile products and saunas.

For the textile products to emit such rays, the fibres or fabrics are required to gain some features. For this purpose, bioseramic powder is applied to the fibres and hence the textile becomes able to emit far infrared rays. This study deals with yarns that have acquired the ability to emit far infrared rays and their usage areas in textile. This review examines bioceramic powders, black body, production of FIR emitting yarns, features of yarns, various usage areas and future trends by means of literature review method.
\end{abstract}

\section{Introduction}

Far infrared radiation qualified as thermal radiation exists within electromagnetic spectrum and the wavelength of these rays range between 710 nanometre and $1 \mathrm{~mm}$ [1]. Infrared radiation is examined in three sections; namely near infrared radiation (NIR), middle infrared radiation (MIR) and far infrared radiation (FIR). Far infrared radiation is between 5.6 and 1000 micron and cannot be seen by human eyes [2]. These rays are emitted by sunlight, human body, metals and some minerals [21], [22]. Far infrared radiation has the feature of increasing blood circulation. With the increase in blood flow, oxygen and food stuffs are carried while carbon dioxide other waste substances move away. FIR rays between 4-14 $\mu \mathrm{m}$ are accepted to be beneficial for cellular growth and this radiation is named "life rays" by some researchers [2]. That far infrared radiation is beneficial for human health encourages its usage in commercial areas. As being one of such usage areas, saunas have been developed, benefiting from treatment features of far infrared radiation [3]. It has been reported that these saunas are used in the treatments of congestive coronary failure, hypertension and obesity [4].

The positive effects of far infrared radiation have also taken the attention of textile engineers and interest in textile designs with these features has increased in recent years. Far infrared radiation fabrics can be obtained in two ways: 1. Adding a bioceramic mineral or a natural or cultivated substance (bamboo charcoal) into a fabric (coating, lamination, pressing etc.) 2. Adding a substance with far infrared feature into polymer matrix during fiber spinning [6-10]. When applied into textile products, bioceramic materials can emit far infrared radiation. [2]. Especially, bioceramic materials can emit rays of 8-14 $\mu \mathrm{m}$ wavelength over $0,9 \varepsilon$ [5]. This study deals with black body emission and yarns that can emit far infrared radiation. Some information on production, usage areas, characteristics and future trends of these yarns has been presented. 


\section{Bioceramics, Bamboo Charcoal and Black Body Emission}

Bioceramics can be defined as ceramics having biological function and they can emit far infrared rays (Figure 1) [2], [23]. Production of FIR textile can generally occur when nano or micro bioceramic powders are added to polymer matrix before the spinning of fibers. These powders are believed to retain and re-emit the rays emitted by body [2]. Some of the bioceramic powders that can be added to the textile structure for far infrared feature include Magnesium oxide $(\mathrm{MgO})$, Zirconium dioxide $\left(\mathrm{ZrO}_{2}\right)$, Aluminium oxide $\left(\mathrm{Al}_{2} \mathrm{O}_{3}\right)$, Iron III oxide $\left(\mathrm{Fe}_{2} \mathrm{O}_{3}\right)$, Silicon dioxide $\left(\mathrm{SiO}_{2}\right)$, Germanium, Titaniumdioxide $\left(\mathrm{TiO}_{2}\right)$, Bamboo charcoal as well as such minerals as nephrite, pearl powder, tourmaline. Bioceramic materials emit FIR to the deep parts of diarthroses and hence blood circulation increases in tissues [9], [24], [25].

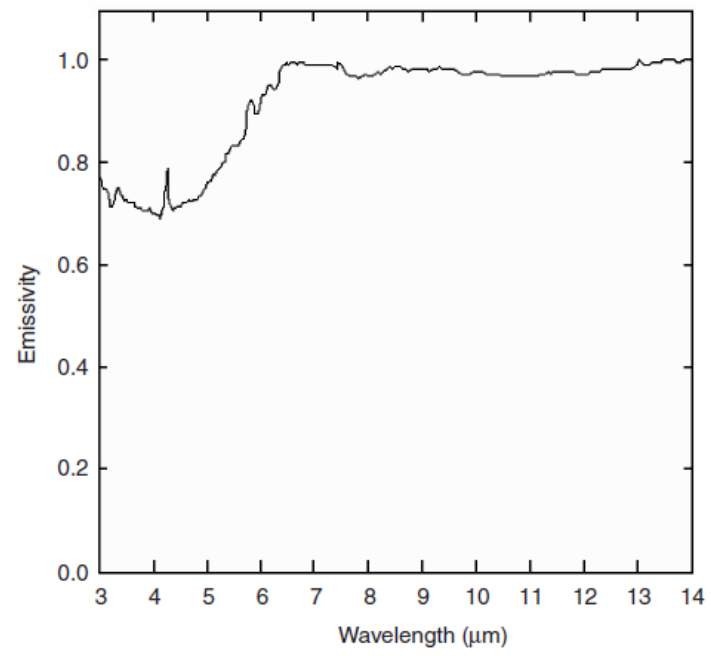

Figure 1. : FIR emission of bioseramic materials. Emission at and above 6 micron is about 0,98 \& [23].

Bamboo charcoal powder is another material that attribute FIR feature to the textile products. Bamboo is generally grown up in low-latitude tropical and subtropical regions [12]. Bamboo charcoal powders are obtained by carbonizing the bamboo plant in ovens at $800-1200{ }^{\circ} \mathrm{C}$ and the harvest of the plant should be made after five years [26]. Bamboo charcoal powders produce far infrared radiation that can be absorbed quickly by human body. Reaching to the deep parts of human body and creating atomic and molecular frictions, these rays can increase internal temperature of the body. In addition, capillary vasodilation and the acceleration in blood circulation enable body temperature to be protected. Bamboo charcoal powders have the feature of anion emission, strong absorption, deodorization and moisture absorption [14].
In many studies, bamboo charcoal powders were used for the textile products to emit far infrared radiation. Fibers with different polymers were obtained from extruder by adding them into polymer matrix. The studies showed that bamboo charcoal powders increased the FIR emissivity rate [8], [12], [14].

The degree of emissivity of FIR materials ranges between 0 and 1. Each material above absolute zero emits IR. Each objects that are exposed to heat emit electromagnetic wave called black body emission. This electromagnetic wave is infrared in room temperature (wavelength: $0.77 \sim 1000 \mu \mathrm{m}$ ). While black body emission is evaluated as 1 , other materials are named as grey body and their emissivity is between 0 and 1 . For instance, human skin: 0.99; tree, wood, water, ice, frost, leaves: 0.97; glass, concrete, brick: 0.94; stainless steel: 0.74; Aluminium: 0.18 [22].

\section{Production of Yarns Emitting Fir and Their Usage Areas}

FIR fibers are wound with various fibers so that yarns gain the property of FIR. [11-17]. FIR fibers are sold in the market with the trade names Celliant ${ }^{\circledR}$, Emana ${ }^{\circledR}, \mathrm{Nilit} \AA$.

The working principle of fabrics obtained by bioceramic-applied fibers is based on the retroreflection of energy with a wavelength of 8-14 $\mu \mathrm{m}$ emitted from human body to the body. To put it differently, the fabric functions as a mirror [2], [18], [19]. The increase in the amount of FIR powders also increases the emissivity of these rays. However, the concentration of FIR powders should not exceed 5\%. Powder concentration above 5\% leads to decrease in the endurance of fibers as well as blockage in nozzles [20].

The effects of FIR on human health include decreasing swelling and ache in muscle and joints, encouraging renewal and quick recovery and improving blood circulation. For this reason, the ideal applications of FIR textiles have a comprehensive area ranging from local pain killers to others areas of supporting a health life. The products include therapeutic knee, elbow, waistbands, gloves, socks, shirt and belts (Figure 2) [2]. FIR clothes designed for sportsmen have been produced in order to regulate sweating, lactic acid and toxins [2]. In a study, it was found out that ceramic powders emitting FIR can decrease muscle tiredness and normalize acidification of strained muscles, which decreased muscle tiredness [23]. They can also increase muscle elasticity and relieves aching and muscle spasms by decreasing 


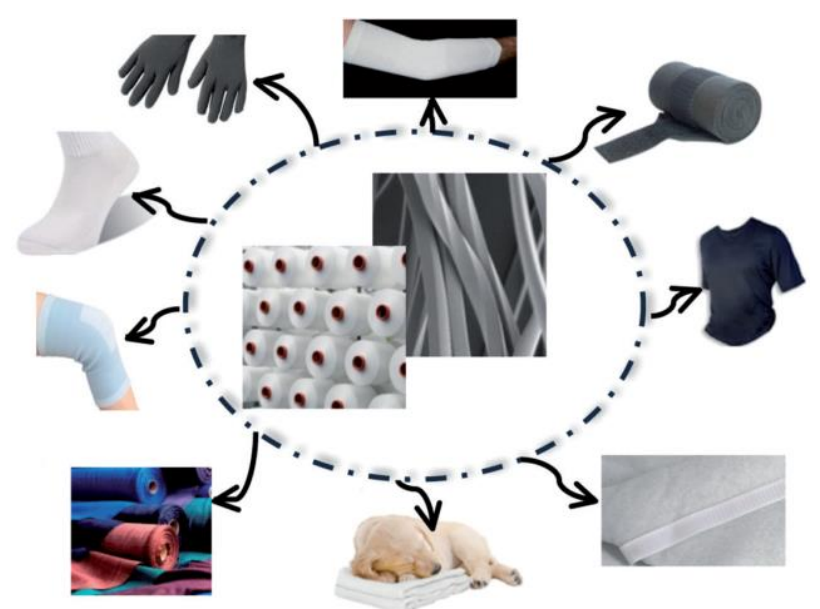

Figure 2. FIR textile products [18].

the risk of injury. FIR textile products can help to heal injured, over engineered muscles, tendons and bonds [2], [27].

In Brazil, a study was carried out on FIR emitting clothes of twenty-one footballer. The yarn used in this study had PA 6-6 yarns with FIR feature and eleven of the footballers wore pyjamas having this feature. The remaining ten people (placebo) wore clothes made from PA 6-6 fiber that did not include FIR. The footballers wore these pyjamas after the training for three nights and slept for ten hours each night. The study showed that it is possible to benefit from FIR clothes in order to quicken recovery of muscle aches of footballers after training [29].

The main therapy function that FIR textiles aim is to encourage microcirculation. FIR therapeutic products have been designed for rheumatoid arthritis, knee ache, shoulder ache, neck ache and all kinds of arthritis [2]. In addition, positive results were obtained in a research on their effect on decreasing cellulitis [28]. FIR finds a place in healthy textile applications because of its property of expelling toxins from the body, stimulating cellular activity, increasing circulation, eliminating ache and swelling. These products are also used commercially in the treatment of Raynaud's syndrome, sprains, fractures, bunions, gout, athlete's foot, psoriasis, poor circulation, chilblains and RSI [2,30].

Ko and Berbrayer made a test on sixty patients with raynaud's syndrome by using two types of gloves. One type of the gloves can emit FIR while the other is of conventional (placebo) type. As a result of the study, in both subjective and objective measures, it was reported that significant improvements were observed in the recovery processes of the ones who wore FIR gloves [31].

The surfaces (membrane) obtained by nano-size fibers have various usage areas in medicine because of specific big surface, small pore size and high porosity. In a study, germanium (Ge) and silicon dioxide $\left(\mathrm{SiO}_{2}\right)$ nano particles were mixed with polyvinyl alcohol and nanofiber surface was obtained. This surface encourages quick recovery in pledgets with its far infrared radiation emission and antimicrobial property as well as having the potential of preventing microbial infection. These products were also found out to have usage potential in medical textiles [33].

FIR fabrics are used in home textiles in such products as bed, blanket, sleeping-bag for improving sleeping quality. In order to improve sleeping-quality, discs that can emit far infrared radiation were placed in bed and blankets. At the end of the study, 350 persons were evaluate sleeping quality subjectively. After using the products, $80 \%$ of the subjects felt themselves well and very well while $63.5 \%$ of them found the product effective and very effective [32].

Textile products that can emit strong FIR are brilliant members for maintaining body temperature. Fabrics emitting FIR can keep the body warm in cold environments. For instance, sleeping pillows giving momentary heat in cool weather and gloves used for warming up the wrist can be examined under this category. Similarly, wool and cotton products impregnated with ceramic powders are available in the market in the form of socks, gloves, jacket and car seat pad. These products are put onto the market with their FIR health benefits in accordance with their marketing goals $[2,30]$.

\section{Fir Yarn Properties and Future Trends}

Bamboo charcoal powders are black in colour as they are produced through carbonization process and hence the produced yarns are also black. However, in a study carried out by Li et al., white yarn was observed by modifying bamboo charcoal powders with titandioxid [8].

In a study carried out by $\mathrm{Li}$ et al. [7], fibers obtained by adding bamboo charcoal to nylon fibers were turned into textile surfaces after being mixed with polyethylene terephthalate (PET) and stainless steel. At the end of the study, the infrared radiation values of the obtained surface came out above 0,85 $\varepsilon$. As the values were above $0,8 \varepsilon$, it was concluded that the obtained fabrics would be beneficial for human health.

In another study carried out by Lin et al. [13], polyester containing bamboo charcoal powders of $1.2 \%$ was wound with stainless steel wire $(40 \mu \mathrm{m})$ and antibacterial nylon. Stainless steel was used as core spun and wound with FIR polyester and 
antimicrobial nylon. Three kinds of fabrics were obtained with these yarns. Fabrics were analysed according to spinning number $(8,11,14 \mathrm{turn} / \mathrm{cm})$ of hybrid yarn. According to far infrared test results, increase in spinning number is in proportionate to far infrared emission. FIR textiles represent a growing and exciting area in functional textiles. As new technologies and supporting studies continue, this area will certainly continue to grow up and create interest [2].

\section{Conclusion}

This study dealt with the effect of far infrared radiation on human health as well as producing yarns that emit such rays. In addition, this study presented some information on basic properties of FIR yarns. It was underlined that these rays are beneficial for human health. The study show up that bioceramic materials can emit these rays and that the fibers obtained through the addition of nanosize bioceramic powders in the extruder during fiber spinning emit FIR rays. These products range from home textile (bed, blanket) to daily used products (socks, gloves), therapeutic textiles (hand, knee and wrist bandages, socks for cellulitis).

\section{References}

[1] B. Demirel, G.A.K. Gürdil, A. Tekgüler, Kızılötesi Dalga-boyundaki Işınlarla Isısal Grafikleme Yöntemi ve Tarımda Kullanılma Olanakları. 25. Tarımsal mekanizasyon kongresi, 1-3 October, 2009 Isparta-Turkey.

[2] J. Dyer, Infrared functional textiles, 184-197, 2011. [Ed. Pan N., Sun G. Functional textiles for improved performance, protection and health. Woodhead Publishing Ltd.] DOI: 10.1533/9780857092878.184

[3] Infrared Saunas, Available: https://infraredsauna.com/infrared-sauna-detox/, Date of access: 10.08.2017.

[4] R. Beever, Do Far-Infrared Saunas Have Cardiovascular Benefits in People with Type 2 Diabetes?. Canadian Journal of Diabetes. 34(2) (2010)

113-118.

DOI: http://dx.doi.org/10.1016/S14992671(10)42007-9

[5] TK. Leung, In Vitro and In Vivo Studies of the Biological Effects of Bioceramic (a Material of Emitting High Performance Far-Infrared Ray) Irradiation, Chinese Journal of Physiology 58(3) (2015) 147-155. DOI: 10.4077/CJP.2015.BAD294

[6] X. Hu, M. Tian, L. Qu, S. Zhu, G. Han, Multifunctional cotton fabrics with graphene/polyurethane coatings with far-infrared emission, electrical conductivity, and ultraviolet blocking properties, Carbon 95 (2015) 625-633. DOI: https://doi.org/10.1016/j.carbon.2015.08.099
[7] JH Lin, YT Huang, TT Li, CM Lin, CW Lou, Manufacture technique and performance evaluation of electromagnetic-shielding/far-infrared elastic warp-knitted composite fabrics, The Journal of the Textile Institute, Vol. 107, No. 4, (2016) 493-503. DOI:

http://dx.doi.org/10.1080/00405000.2015.1045253

[8] QS Li, MS Xu, GJ Zhou, LQ Wang, Preparation and characterization of white bamboo charcoal PET fiber, Chinese Chemical Letters 21 (2010) 995-998. DOI: https://doi.org/10.1016/j.cclet.2010.01.022

[9] S. Wang, Y. Zhang, H. Liu, Wear Comfort Evaluation of Pearl-Cellulose Fabrics, Advanced Materials Research 175-176 (2011) 480-484. DOI: 10.4028/www.scientific.net/AMR.175-176.480

[10] YM. Park, JW. Shin, Surface Properties Studies of MPCMs Containing Fabrics for Thermo-regulating Textiles, Fibers and Polymers Vol.12, No.3 (2011) 384-389. DOI: https://doi.org/10.1007/s12221-0110384-x

[11] CW. Lou, JH Lin, Evaluation of Bamboo Charcoal/Stainless Steel/TPU Composite Woven Fabrics, Fibers and Polymers 12, 4 (2011) 514-520. DOI: https://doi.org/10.1007/s12221-011-0514-5

[12] JH Lin, YT Huang, TT Li, CM Lin, CW Lou, Bamboo charcoal/phase change material/stainless steel ring-spun complex yarn and its far-infrared/ anion-releasing elastic warp-knitted fabric: Fabrication and functional evaluation, Journal of Industrial Textiles 46, 2 (2015) 624-642. DOI: https://doi.org/10.1177/1528083715595007

[13] JH Lin, ZC Yu, JF Zhang, CW Lou, Manufacturing Techniques and Functional Properties of the Bamboo Charcoal/ Antibacterial/ Stainless Steel Metal Composite Woven Fabric, Advanced Materials Research 910 (2014) 238-241. DOI: 10.4028/www.scientific.net/AMR.910.238

[14] JH Lin, AP Chen, CT Hsieh, CW Lin, CM Lin, CW Loy, Physical properties of the functional bamboo charcoal/stainless steel core-sheath yarns and knitted fabrics, Textile Research Journal 81(6) (2015) 567 573. DOI: $10.1177 / 0040517510385173$

[15] YL Hsing, WH Hsing, CT Hsieh, JH Lin, CW Lou, Composite Environmentally Protective Sandwich Insulation Material Design. The 13th Asian Textile Conference, 763-766, 3-6 November, 2015 Geelong, Victoria, Australia.

[16] MA Pooley, DM Anderson, HW Beckham, JF Brennan, Engineered emissivity of textile fabrics by the inclusion of ceramic particles, Optics Express 24, 10 (2016). DOI:10.1364/OE.24.010556

[17] YH. Shih, JH. Lin, CT. Hsieh, CW. Lin, CW. Lou, Far-Infrared Nonwoven Fabrics Made of Various Ratios of Bamboo Fiber to Far-Infrared Fiber: FarInfrared Emissivity and Mechanical Property Evaluations, The 13th Asian Textile Conference, 830-834, 3-6 November, 2015 Geelong, Victoria, Australia.

[18] F. Vatansever, MR. Hamblin, Far infrared radiation (FIR): Its biological effects and medical applications, Photon Lasers Med 1(4) (2012) 255266. DOI 10.1515/plm-2012-0034 
[19] A. Vathare, Far-infrared Rays Reflecting Fabrics for Improving the Performance of Human body, D. K. T. E. Society's Textile \& Engineering Institute, Department Of Textiles, Ichalkaranji, 2014.

[20] YS. Lin, HC. Pan, CT. Lee, TK. Leung, Manufacturing method for a far infrared substrate, Patent Appl. 20080217163A1, Sept 11, 2008.

[21]https://tr.wikipedia.org/wiki/K\%C4\%B1z\%C4\%B11 \%C3\%B6tesi, Date of Access: 18.02.2017

[22] Emissivity Measure TSS-5X, Instruction Manual, Japan Sensor Corporation

[23] TK Leung, CM Lee, SY Tsai, YC Chen, JS Chao, A Pilot Study of Ceramic Powder Far-Infrared Ray Irradiation (cFIR) on Physiology: Observation of Cell Cultures and Amphibian Skeletal Muscle, Chinese Journal of Physiology 54(4) (2011) 247254, DOI: 10.4077/CJP.2011.AMM044

[24] Biocera, Available: http://biocera.co.kr/far-infraredray-bioceara-sb.html, Date of Access: 07.08.2017

[25] D. Cobb, Ancient wisdom inspires 'responsive' Far Infrared fibres. Available: http://www.innovationintextiles.com/ancientwisdom-inspires-responsive-far-infrared-fibres/2 Date of Access: 27.12.2016.

[26] Bamboo charcoal, Available: https://en.wikipedia.org/wiki/Bamboo_charcoal, Date of Access: 08.01.2017.

[27] T. Furuta, Y Shimizu, Y Kondo, Evaluating the Temperature and Humidity Characteristics of a Solar Energy Absorbing and Retaining Fabric, Textile Research Journal, 66(3) (1996) 123-130. DOI: https://doi.org/10.1177/004051759606600301

[28] P. Richelmi, FM Bianchi, C. Angelinetta, Evaluation of the cosmetic effect of a pantyhose which helps to reduce imperfections caused by cellulite and local adiposities. The evaluation was carried out through a clinical test, Bio basic Europe, Milan-Italy.

[29] I. Loturco, CCC. Abad, FY. Nakamura, SP. Ramos, R. Kobal, S. Gil, LA. Pereira, FHP. Burini, H. Roschel, C. Ugrinowitsch, V. Tricoli, Effects of far infrared rays emitting clothing on recovery after an intense plyometric exercise bout applied to elite soccer players: a randomized double-blind placebocontrolled trial, Biol. Sport 33 (2016) 277-283. DOI: $\underline{10.5604 / 20831862.1208479}$

[30] Far Infrared Health, Available: https://farinfraredhealth.com, Date of Access: 07.08.2017

[31] GD. Ko, D Berbrayer, Effect of ceramicimpregnated "thermoflow" gloves on patients with Raynaud ' s syndrome: randomized, placebocontrolled study, Altern Med Rev. 7(4) (2002) 328335.

[32] S. Inoue, M. Kabaya, Biological activities caused by far-infrared radiation, Int $\mathrm{J}$ Biometeorol 33(3) (1989) 145-150.

[33] Chung J., Lee S., 2014. Development of Nanofibrous Membranes with Far-Infrared Radiation and their Antimicrobial Properties. Fibers and Polymers, Vol.15, No.6, 1153-1159, DOI 10.1007/s12221-014-1153-4. 